Revista de Ensino em Artes, Moda e Design

Dossiê 4

Currículo: espaço de reflexão e poder

\title{
GAMIFICAÇÃO: ESTRATÉGIA DE ENSINO E APRENDIZAGEM EM CURRICULO POR COMPETÊNCIAS
}

\section{Taísa Vieira Sena ${ }^{1}$}

\footnotetext{
1 Doutora em Comunicação e Semiótica (PUC-SP), mestre em Design (Anhembi-Morumbi), especialista em Marketing e Gestão Empresarial (UFSC) e bacharel em Moda (UDESC). Professora dos cursos de Graduação em Design e coordenadora da Educação Continuada na PUCPR. Diretora Executiva da Associação Brasileira de Estudos e Pesquisa em Moda - Abepem e vice-presidente do Congresso Brasileiro de Iniciação Científica em Design e Moda.

E-mail: taisavieira13@gmail.com | Lattes: http://lattes.cnpq.br/6682366416686468
} 


\section{Resumo}

A busca por excelência na graduação deve ser uma das prioridades no panorama do ensino atual. Para isso, toda comunidade acadêmica necessita estar preparada para enfrentar os desafios advindos do contexto sociocultural contemporâneo, procurando se adaptar às exigências do meio social ou alterá-las de forma positiva, quando for possível. Para tanto, é necessário levantar informações e traçar um diagnóstico das condições sociais e culturais, o envolvimento de todas as partes que constituem a universidade em um trabalho constante e duradouro que possa se converter em procedimento habitual às estratégias elaboradas coletivamente. $\mathrm{O}$ presente artigo tem por objetivo discutir $\mathrm{O}$ cenário atual da educação em nível graduação e suas mudanças para um ensino por competências. São abordadas diferentes estratégias de ensino e aprendizagem com foco em metodologias para aprendizagem ativa, porém, o destaque se dá ao uso da gamificação. $O$ texto traz ainda um relato de experiências em uma disciplina que mostra numericamente os dados positivos do uso da metodologia.

Palavras-Chave: Currículo por competências. Aprendizagem ativa. Gamificação. 


\section{INTRODUÇÃO}

A Educação do século XXI tem grandes desafios e podemos destacar como o maior deles, a preparação dos estudantes para um futuro desconhecido e altamente mutável. Nos encontramos em um ambiente cada vez mais complexo e competitivo, o chamado Mundo VICA - Volátil, Incerto, Complexo e Ambíguo - (BRASILIANO, 2014). Uma realidade desafiadora com enormes pressões e que cria ao mesmo tempo inúmeras oportunidades para indivíduos e empresas que precisam produzir mais com menos recursos, que precisam engajar seus colaboradores para aumentar a produtividade e suas vantagens competitivas. O sucesso neste contexto exige flexibilidade, sensibilidade cultural, confiança, adaptabilidade a mudanças, execução ágil e colaboração. É imprescindível que o profissional do amanhã tenha um perfil multifacetado e protagonista alinhado às expectativas do mundo, sejam elas quais forem dadas a instabilidade e as incertezas já anunciadas com relação ao futuro.

A Oxford Economics (líder mundial em prospecção global e análise quantitativa para negócios e governo) em parceria com a consultoria Towers Watson (líder global em serviços profissionais) realizou um estudo mapeando as competências profissionais exigidas nos próximos anos. Este estudo destaca que a exigência por novas competências é o reflexo das mudanças que estão acontecendo nas empresas, como consequência "do realinhamento da economia, dos avanços da tecnologia, da globalização dos mercados, das mudanças nas tendências demográficas, das novas necessidades dos consumidores e do aumento da competitividade" (FONSECA, 2012).

As competências foram classificadas em "digitais", "pensamento ágil", "comunicação" e "operações globais". Dentre as vinte habilidades listadas pelo estudo, ressaltamos que as que seguem são de fato imprescindíveis para o sujeito profissional do futuro: capacidade para trabalhar de forma virtual; desenvoltura em considerar e se preparar para múltiplos cenários; agilidade para trabalhar com complexidade e atento às ambiguidades; vivacidade para enfrentar os paradoxos de gestão, equilibrando pontos de vista opostos; destreza em ver o cenário como um todo; fluidez nas proposições de cocriatividade e brainstorming; orientação de equipe (incluindo equipes virtuais); senso de colaboração; agilidade na comunicação oral e escrita; habilidade de administrar equipes diversas; sensibilidade cultural

Outro estudo realizado em 2012, PISA (Programme for International Student Assessment), com estudantes de quinze anos, avaliou a capacidade dos mesmos de aplicar os conhecimentos adquiridos (em matemática, leitura, ciência e resolução de problemas) em diferentes cenários dentro ou fora da escola. O PISA dá ênfase às habilidades gerais de raciocínio, de ordenar os processos de resolução de problemas e empenho em resolvê-los. Da mesma forma que o mapeamento realizado pelos ingleses, os resultados do PISA também defendem que é necessário mais do que o domínio de um repertório de fatos e processos para que os estudantes estejam preparados para o mundo de amanhã. Para ter sucesso no cenário atual é preciso se tornar eterno aprendiz, e estar apto a lidar com situações incomuns em que o resultado de suas intervenções é imprevisível. Segundo OECD (Organisation for Economic Co-operation and Development) 2014, organização que promove a avaliação do PISA, os estudantes precisam estar aptos a pensar flexível e criativamente sobre como ultrapassar os obstáculos que estão no caminho para poder resolver problemas desconhecidos. 
Ambos estudos apontam, portanto, necessidades de habilidades diferenciadas que o ensino tradicional, com foco em aulas expositivas e com característica conteudista não contempla e indica a necessidade de mudanças, tanto nos currículos como nas metodologias de ensino e aprendizagem. O PISA elenca algumas abordagens que podem promover aprendizagem com profundidade e preparar o estudante para aplicar seus conhecimentos em situações diferentes das quais se apropriou dos mesmos. Dentre elas, destacam-se: "aprendizagem baseada em problemas"; "aprendizagem baseada em pesquisa"; "aprendizagem baseada em projetos" (individual ou em grupo); "aprendizagem baseada em times" e a "gamificação".

Essas abordagens são definidas pelo engajamento do estudante no processo de aprendizagem e conhecidas como metodologias que promovem a aprendizagem ativa. Este modelo demanda do estudante a realização de atividades significativas e o raciocínio e reflexão sobre o que estão fazendo. Para Prince (2004), os principais pontos destas abordagens são a participação ativa e engajamento do estudante nas atividades em sala de aula. Para criar este engajamento nas atividades em sala de aula, o foco é transferido do professor para o estudante, ou seja, deve-se colocar o estudante no papel de protagonista.

\section{CURRICULO POR COMPETÊNCIAS, APRENDIZAGEM ATIVA E GAMIFI- CAÇÃO}

Uma busca pela etimologia do termo competência nos leva ao latim competentia, e a sinônimos como "proporção", "justa relação", aptidão, idoneidade, faculdade que a pessoa tem para apreciar ou resolver um assunto. Teria surgido pela primeira vez na língua francesa, no século XV, designando a legitimidade e a autoridade das instituições para tratar de determinados problemas. No século XVIII seu significado se amplia para o nível individual, designando a capacidade devida ao saber e à experiência.

No contexto da educação, competência surge como alternativa à capacidade, habilidade, aptidão, potencialidade, conhecimento ou savoir-faire. A competência permite ao estudante enfrentar e regular adequadamente um conjunto de tarefas e de situações educativas. Com efeito, o estudante se mostracomo como protagonista do processo e passa a aprender muito mais por si do que através do professor, a construção do saber é pessoal e se dá pela interação. Costa (2014) afirma que um currículo estruturado desta forma enaltece o conhecimento como instrumento de aquisição de competências e prevê os conteúdos como meios possibilitadores de desenvolvimento das competências previstas na ação. Além de valorizar o método pedagógico e a aprendizagem ativa, superando a dicotomia teoria-prática e enraizando os valores educativos da escola do século XXI.

Segundo Perrenoud (2001), o ensino por competências torna necessário mudanças na representação curricular e na prática docente. Isso pressupõe uma pedagogia ativa, cooperativa, na qual os professores vejam o ato de ensinar como conceber, encaixar e regular situações de aprendizagem, seguindo os princípios pedagógicos ativos construtivistas. Sendo assim, uma organização curricular por competências supõe, então: mudança na postura metodológica da ação pedagógica docente que engloba estratégias e novas metodologias de ensino; e, foco na construção de competências, avaliação por competências e adoção de um contexto interdisciplinar do ensino.

Para propor um currículo por competências, não podemos nos basear exclusiva- 
mente na tradicional organização curricular por objetivos, ementas e disciplinas. E, no caso das últimas, é preciso atentar para seu caráter pluri, inter e transdisciplinar num contexto de transversalidade dos conhecimentos. Desse modo, conteúdos disciplinares deverão se constituir num meio, ou seja, num suporte para a construção de competências e não num fim em si.

Em seu PDG (Plano de Desenvolvimento da Graduação) a PUCPR (2018), descreve a competência como um saber-agir baseado na mobilização e utilização interiorizadas e eficazes de um conjunto integrado de recursos, para resolução de uma família de situações-problema. Para a universidade, cada disciplina dos cursos tem uma contribuição específica para o desenvolvimento das competências do egresso, as quais são avaliadas em pontos específicos do currículo.

A tríade dos saberes na universidade que contemplam uma competência se forma com forte embasamento teórico (saber-saber), permeado pela prática (saber-fazer) e se completa com o saber-ser que é sustentado pelos cinco princípios norteadores da graduação (autonomia, dedicação, cooperação, honestidade e senso crítico). Esse processo se dá pela aprendizagem ativa, ela é o meio para o desenvolvimento de competências e, por consequência, de aprendizagens significativas e duradouras. Dessa forma, quanto mais protagonismo do estudante houver em uma metodologia de ensino, maior a chance de formação de alguém capaz de ser um aprendiz ao longo da vida. O contexto da universidade citada acima vai ao encontro com a afirmação de Leite que construir um currículo baseado em competências significa, antes de tudo, "[...] educar os alunos para um fazer reflexivo e crítico, no contexto de seu grupo social, questão que coloca a educação a serviço das necessidades reais dos alunos para sua vida cidadã e sua preparação para o mundo do trabalho" (LEITE, 2004, p.126).

Consideramos então, que um currículo por competências possibilita mudança de métodos tradicionais utilizados dentro da sala de aula, requer uma reformulação de metodologias de ensino e aprendizagem e sinaliza a necessidade de um constante diálogo entre sujeitos. A reformulação dos métodos de ensino e aprendizagem faz com que o professor se utilize de seus conhecimentos e reflita sobre suas ações depositando mais confiança no potencial de seus estudantes, neste processo ganham peso também as trajetórias individuais e as experiências coletivas de cada um.

O currículo por competências está fundamentado a redefinição do sentido dos conteúdos de ensino, de modo a atribuir sentido prático aos saberes acadêmicos, abandonando a superioridade dos saberes disciplinares para se centrar em competências verificáveis em diversas situações. Essas competências devem ser definidas com referência a problemáticas que os estudantes deverão ser capazes de compreender e dominar. A definição destas situações deve estar atrelada ao perfil do egresso que se quer formar, somente após essas definições é que se selecionam os temas e conteúdos de ensino. Em resumo, em vez de partir de uma lista de conteúdos disciplinares existentes, com base no qual se efetuam escolhas para garantir os conhecimentos considerados mais importantes, a construção do currículo por competências parte do perfil do egresso, da análise de situações concretas e da definição de competências requeridas por essas situações, recorrendo às disciplinas somente na medida das necessidades exigidas pelo desenvolvimento dessas competências. Em cada disciplina os estudantes adquirem conhecimentos que lhe levarão adquirir elementos que juntos formarão as competências. 
Na elaboração de um currículo orientado por competências não deve haver a hierarquização do saber entre o teórico e o prático ou entre o geral e o técnico ou puro e o aplicado e sim uma integração entre eles. As competências podem ser vistas como unidades para as quais convergiriam e se entrecruzariam um conjunto de elementos que as estruturam (conhecimentos, habilidades e valores). Compreender a competência como o ponto de convergência entre conhecimentos, habilidades e valores incorpora o conceito de que a competência constitui um constructo de que os elementos isolados perdem esse sentido. Assim sendo, identificamos duas características implícitas ao significado de competência: a primeira, com o foco no desempenho (produto), e segunda, na recuperação/criação de condições em que este desempenho é relevante (processo).

A construção de currículos por competência seleciona conteúdos autênticos que possam ser mobilizados em situações práticas de aprendizado. O contexto educacional deve procurar refletir a vida profissional, considerando as diversas dimensões de seu exercício junto à sociedade. A proposta é trazer a prática e o desenvolvimento da identidade profissional para o centro das atividades de aprendizado (atividades dentro do contexto real), preocupando-se com a identificação e adequação de processos que conduzam aos resultados. O modelo não exclui a organização disciplinar que ocorre no currículo tradicional, mas estabelece competências que são desenvolvidas na esfera de diferentes disciplinas ou nas diversas relações existentes entre elas. Voltar-se para as competências não desobriga o currículo de pensar sobre o conhecimento, sobre a sua absorção e incorporação no cotidiano da vida acadêmica. Mas propõe fazê-lo integrado ao processo de formação do estudante de forma inovadora, criativa, instigante, crítica e reflexiva.

A competência surge quando, diante de uma situação, o sujeito é capaz de mobilizar adequadamente diversos conhecimentos prévios, escolher e integrá-los de forma acertada à situação em questão. Sendo assim, a competência exige apropriação concreta e extensa de saberes, de modo a permitir ao sujeito que os convoque (de forma ajustada) quando se encontra face a diferentes situações e contextos. Advém das noções, conhecimentos, informações, procedimentos, métodos e técnicas integrados. Para Scallon (2015), a competência acolhe saberes, atitudes e valores, abarcando o domínio do self (saber-ser), o domínio cognitivo (saber formalizado) e o domínio comportamental (saber-fazer), a competência consolida-se numa ação ou no conjunto de ações organicamente articuladas.

A competência se caracteriza por ser complexa, projetada no futuro (numa aposta nos poderes do tornar-se), e se apresenta como uma possibilidade de forjar novas formas de organização e de reinvenção de práticas de ensino-aprendizagem libertadoras, que possam encaminhar egressos ativos, críticos, capazes de melhorar o meio onde vive com suas ações. Como uma combinação de conhecimentos, motivações, valores e ética, atitudes, emoções, a competências, tem também componentes de carácter social e comportamental que, em conjunto, podem ser movimentados para suscitar uma ação eficiente num contexto particular. Além disso ela permiti a gestão de situações complexas e instáveis que exigem recorrer ao distanciamento, à metacognição, à tomada de decisão, à resolução de problemas complexos.

No campo acadêmico, solicita-se a professores e estudantes que mobilizem seus conhecimentos prévios (pessoais, sociais, técnicos, dentre outros) ante situações diver- 
sas, complexas e imprevisíveis. Espera-se aptidão para interagir com os desafios atuais (e futuros), em prol de uma conexão que combina recursos e ações do sujeito e traduz uma contribuição pessoal para um determinado desfecho, ou seja, pôr o conhecimento em ação Costa (2004) defende que o sujeito é produtor e portador de competências, visto que ele é detentor de um conjunto de valores (como a colaboração, o empenho ou a mobilidade) que precisarão ser mensurados na abordagem às competências.

Currículos por competência devem ser compostos por metodologias de ensino-aprendizagem com foco ativo, práticas pedagógicas, diferentes contextos e cenários de aprendizagem, métodos de avaliação e atividades de pesquisa com esse princípio de organização curricular. Tipicamente, são focados na busca ativa pelo conhecimento, interdisciplinaridade, integração teórico-prática e interação ensino-sociedade, trazendo o desenvolvimento da identidade profissional para o centro das atividades de aprendizado para que ele seja significativo. Para o desenvolvimento deste tipo de currículo é preciso inicialmente, a identificação e definição das competências necessárias à boa prática profissional. Em seguida, a definição de seus componentes e os níveis de desempenho. Também, deve ser construído um programa de avaliação que esteja voltado para o aprendizado (avaliação formativa) e que seja focado para a detecção de conhecimentos, habilidades e atitudes assimilados pelos estudantes.

Para que a transição de um currículo tradicional para um currículo por competências ocorra de forma consistente, é preciso ter claro o conceito de competências; refletir como os estudantes poderão desenvolver tais competências; definir o perfil do egresso que pretende formar, identificando quais competências traduzem essa ideia e, em consequência, quais os conteúdos curriculares que deverão contribuir para a formação delas (quais são os elementos formadores da competências); selecionar temas, conteúdos e metodologias que melhor fundamentem as competências determinadas para cada currículo; definir qual o tipo de organização curricular, podendo-se optar por temas, projetos ou problemas, integrando disciplinas ou áreas do conhecimento; e ter claro que a interligação do conhecimento é uma das estratégias que favorece o desenvolvimento de competências. Dallan (2000) afirma que para desenvolver competências é fundamental propor atividades desafiadoras, que possibilitem ao estudante mobilizar e colocar ação os conhecimentos já internalizados ao mesmo tempo em que ele deve buscar novos conhecimentos.

O currículo por competências exige mudanças no processo de ensino e aprendizagem, pede metodologias de ensino diferentes das tradicionais, conhecidas como metodologias para aprendizagem ativa. Até mesmo a sala de aula precisa ser repensada na sua estrutura e na abordagem pedagógica a qual tem sido utilizada. Em oposição à aprendizagem passiva, bancária, baseada na transmissão de informação, na aprendizagem ativa, o estudante assume uma postura mais dinâmica, na qual ele resolve problemas, desenvolve projetos e, com isto, cria oportunidades para a construção de conhecimento.

O estudante é figura central e o maior responsável pelo processo de aprendizado, neste tipo de metodologia. Sendo assim, o objetivo desse modelo de ensino é incentivar que a comunidade acadêmica desenvolva a capacidade de assimilação de conteúdos de maneira autônoma e participativa. Os principais elementos desta abordagem são a participação ativa e engajamento do estudante nas atividades em sala de aula. A apren- 
dizagem ativa solicita do estudante a realização de atividades significativas e o raciocínio e reflexão sobre o que está fazendo. Isto é incentivado a transferência do foco do professor para o estudante, pois, ele passa a participar ativamente das atividades, a aula deixa de ser centrada no professor e passa a ser centrada no estudante. Brent e Felder (2009) afirmam que a aprendizagem ativa é assinalada por atividades nas quais os estudantes são solicitados a fazer, e não apenas assistir, ouvir e tomar notas. Os autores salientam que na aprendizagem ativa o professor não deixa de ter momentos de exposição e explanação, no entanto o professor deve planejar atividades de curta duração para realizar entre os momentos de explicação. Envolver os estudantes em atividades entre as explanações, os mantém atentos ao que está sendo trabalhado em sala de aula.

Prince (2004) nos leva a compreender que aprender ativamente significa ter que pensar, entender e formar a própria opinião. Através deste método de ensino-aprendizagem, o estudante desenvolve diversas habilidades. A aprendizagem ativa se mostra vantajosa tanto para os estudantes como para os professores. Para os primeiros, identificamos: o desenvolvimento do pensamento crítico, a facilidade para reter o conhecimento, maior motivação, estímulo à autonomia, desenvolvimento da autoconfiança, maior facilidade para a resolver problemas, sentimento positivo de serem protagonistas do próprio aprendizado e melhores resultados acadêmicos de maneira geral. Já para os professores e para universidade a aprendizagem ativa é uma apropriada para melhorar o acompanhamento e a avaliação dos estudantes. Por meio dessa técnica é possível mapear as necessidades e dificuldades de cada estudante, abrindo caminho para abordagens individualizadas. A aprendizagem ativa proporciona ainda: a possibilidade de realizar um melhor acompanhamento pedagógico, maior facilidade para lidar com os alunos no ambiente da sala de aula, maior interesse dos estudantes pelo aprendizado e aumento do engajamento de maneira geral. Os usuários destas metodologias advertem que a assertividade dos resultados desta abordagem está relacionada com o período de atenção do estudante despendido nas atividades durante a aula.

A efetividade da aprendizagem ativa se baseia também pirâmide de aprendizagem de William Glasser para explicar como as pessoas geralmente aprendem e qual a eficiência dos métodos nesse processo. Para o psiquiatra americano, aprendemos e assimilamos $10 \%$ quando lemos o conteúdo proposto $20 \%$ quando ouvimos, $30 \%$ quando vemos e, por fim, $50 \%$ quando vemos e ouvimos, de forma que os métodos tradicionais de ensino devem ser repensados. Estes números aumentam (cerca de 70\%) quando debatemos. Em atividades de experimentação a retenção dos conteúdos passa para $80 \%$. O aprendizado é ainda maior, chegando a $95 \%$ quando ensinamos uns aos outros o que foi aprendido. Está aqui o verdadeiro diferencial: ensinar para que esse conteúdo seja efetivamente assimilado. Assim devemos criar contextos para que os estudantes possam ensinar uns aos outros e promover experimentações, colocando a teoria na prática.

Diversas estratégias têm sido utilizadas para promover a aprendizagem ativa como a aprendizagem baseada na pesquisa, o uso de jogos ou o problem based learning $(\mathrm{PBL})$, project based learning ( $\mathrm{PjBL})$, team based learning (TBL), flipped classrom dentre outras. Diferentes universidades têm adotado uma ou mais destas estratégias em algumas disciplinas. Estas universidades têm inovado seus métodos de ensino, procurando adequá-los para que possam explorar os avanços das tecnologias educacionais, bem como minimizar a evasão e o nível de reprovação. 
Flipped Classroom ou sala de aula invertida é baseada nos conceitos de aprendizado ativo, engajamento de estudantes, educação híbrida, leitura, vídeos e podcacsting de aulas em casa antes da aula presencial. Ao fazerem isso, os próprios estudantes colaboram para que o tempo em sala de aula seja dedicado à realização de exercícios, projetos e discussões nas quase os professores têm a função de serem mentores, incentivar perguntas e debates e encorajar trabalhos em grupos EDUCAUSE (2012).

Peer Instruction (numa tradução livre, "instrução entre pares"), proposta pelo Professor Eric Mazur, professor de Física da Universidade de Harvard em 1991, que prima pelo entendimento e aplicabilidade dos conceitos, utilizando-se da discussão entre os estudantes. O professor Mazur defende que o primeiro passo da aquisição do conhecimento de determinada área é o entendimento e a apreensão conceitual. Os estudantes devem ter o domínio conceitual, para desenvolver suas habilidades e aplicá-lo nas situações práticas - que é, na realidade, o esperado do profissional em sua atuação.

A aprendizagem baseada em projetos ou project based learning (PjBL) busca fazer com que os estudantes adquiram conhecimento por meio da solução colaborativa de desafios (BEHRENS, 2001). O estudante precisa pesquisar e se esforçar para explorar as soluções possíveis dentro de um contexto específico, usando diferentes recursos disponíveis, o que incentiva a capacidade de desenvolver um perfil investigativo e crítico perante alguma situação. O professor mediador não deve explicar todos os conteúdos, a fim de que os alunos busquem os conhecimentos por si mesmos. Porém, é necessário que o educador dê um feedback nos projetos e mostre quais foram os erros e acertos. É importante ressaltar que a avaliação deve ser feita do processo e não apenas do produto.

Aprendizagem Baseada em Problemas ou problem based learning (PBL) tem por objetivo tornar o estudante capaz de construir o aprendizado com base em conceitos, processos e atitudes por meio de problemas propostos que o expõe a situações motivadoras e o prepara para o mundo do trabalho. Este tipo de aprendizagem é focada na parte teórica da resolução de casos (YADAV, 2011).

Team based learning (TBL), ou aprendizagem entre times, tem como ponto focal a formação de equipes dentro de determinada turma para que o aprendizado seja feito em conjunto e haja compartilhamento de ideias. O TBL pode ser usado em conjunto com diferentes metodologias como aprendizagem por projeto, problema ou baseada em jogos; o objetivo é que os estudantes resolvam os desafios e trabalhem juntos, o que é benéfico na busca pelo conhecimento. Com trabalho em equipes a e ajuda mútua, pode-se aprender e ensinar ao mesmo tempo, formando o pensamento crítico, que é construído por meio de discussões embasadas e levando em consideração opiniões divergentes.

O uso de jogo ou gamificação ganhou destaque como estratégia de ensino-aprendizagem nos últimos anos. A metodologia implica em usar elementos dos jogos de forma a engajar os estudantes para atingir um objetivo. O potencial da gamificação é imenso, pois ela desperta o interesse, aumenta a participação, auxilia o estudantes a desenvolver criatividade e autonomia, promover diálogo e resolver situações-problema complexos. Os jogos são usados como ferramentas que apoiam as aulas, pois permitem treinar, ensinar, aprender e identificar elementos que não são fornecidos com métodos tradicionais. Jogos para ensino são também potenciais melhoradores do processo no qual estão inseridos, sendo assim, eles devem estar em constante evolução, buscando incorporar as melhorias e sugestões dos usuários dessas ferramentas. Segundo Deterding (2011), 
os jogos como propostas do ensino fornecem aspectos práticos que o ensino tradicional de aulas expositivas não provê, com pouca interação dos estudantes. Ensinar usando jogos pode ser uma atividade lúdica que é bastante motivadora no processo de ensino-aprendizado. Os jogos para ensino são uma poderosa ferramenta de aprendizagem, na medida em que o estudante é estimulado a participar, auxiliando professores em simular ambientes reais, melhorando o desempenho dos estudantes e estimulando a geração de experiências individuais, coletivas e sociais, que ajudam na formação dos profissionais.

O sucesso do uso de jogos como estratégia de ensino-aprendizagem pode ser explicado com base no livro de Huizinga (1971) Homo Ludens. Para o autor, o jogo é uma ação que se desenvolve dentro de certos limites de lugar, tempo e vontade, seguindo certas regras livremente aceitas. Durante o jogo é importante que os estudantes tenham motivação e emotividade, seja por diversão ou competição. O percurso do jogo por vezes deve estar acompanhado de tensão. No entanto, sempre provoca alegria e relaxamento. O autor afirma ainda que o jogo é condição da existência da própria cultura e é inerente à natureza humana, ou seja, sem certo desenvolvimento de uma atitude lúdica, nenhuma cultura é possível.

A gamificação está relacionada com a ideia de engajamento, narrativas, autonomia e significado. Inclui desafio, senso de controle, tomada de decisão e senso de domínio. Todas essas são características intrínsecas dos jogos que são bastante valorizadas. Podemos considerar que jogos são ambientes ideais para a aprendizagem, pois são construídos com permissão para erros e encorajam os jogadores a pensar. Mas não é só o senso de engajamento o ponto alto do uso de jogos para ensino, também a retroalimentação imediata, a sensação de acompanhamento e a procura de um objetivo desafiador e de superação. O uso de jogos em sala de aula são estratégias de grande valor para o desenvolvimento de competências dos estudantes considerando não só a motivação que eles podem gerar, mas também o tempo de diversão que proporcionam.

\subsection{Experimento na disciplina de Tecnologia Têxtil Aplicada}

A disciplina de Tecnologia Têxtil Aplicada, assim como Tecnologia Têxtil (sua precedente), era compreendida como basicamente teórica e sendo ministrada por aulas expositivas na PUCPR até o segundo semestre de 2017. Do ponto de vista dos estudantes era "uma disciplina difícil e com muita coisa para decorar", consequentemente com um grande número de estudantes em exame ou reprovados. Conhecer as fibras e tecidos, seus processos produtivos e suas características é fundamental para qualquer designer de moda, o que não vinha ocorrendo com muito sucesso. Neste contexto, o grande desafio para a professora era como tornar a disciplina mais interessante para os estudantes e engajá-los no processo de aprendizagem de algo que eles achavam tão difícil. O caminho escolhido foi passar a trabalhar a disciplina a partir de metodologias que levassem a uma aprendizagem ativa. Uma aprendizagem que estivesse relacionada ao contexto e à cultura dos jovens estudantes, que desenvolvesse a sua criticidade, a ética, a autonomia, a reflexão e a investigação, para assim tornarem-se participantes da ação educativa.

As modificações na disciplina de Tecnologia Têxtil Aplicada do curso de Design de Moda da PUCPR foram programadas durante 6 meses e com acompanhamento do CrEAre (Centro de Ensino e Aprendizagem), que é um núcleo de desenvolvimento do- 
cente vinculado à Diretoria de Suporte à Graduação, da Pró-Reitoria de Graduação da Pontifícia Universidade Católica do Paraná, como parte de um grande projeto de inovação financiado pela FINEP ${ }^{1}$. O processo de transformação da disciplina iniciou com a reformulação do plano de ensino, metodologias de aprendizagem e avaliação focada em indicadores de desempenho que levam aos resultados de aprendizagem que contribuem para formação por competências.

Segundo Sena (2018a) as mudanças na disciplina (que era totalmente teórica) ocorreram em resposta ao novo estudante que processa as informações de forma diferente hiperconectados, seguros de si e "empoderados". Os jovens nascidos entre 1994 e 2010, conhecidos como Geração Z, têm exigido e provocado mudanças na educação, segundo o Observatório de Tendências de Coolhunting Community da Espanha (2016). Segundo o observatório, os estudantes atuais se enquadram no perfil "power pupils" (alunos "empoderados"), são cada vez mais conscientes de suas capacidades e talentos. São confiantes, têm imaginação e não são passivos em sala de aula, sendo movidos para trabalhar com realização pessoal. Então é preciso cativar este estudante para que ele se engaje no processo de aprendizagem.

Neste contexto, Coolhunting Community identificou quais são as tendências em educação que devem inspirar as discussões sobre o ensino. Para os pesquisadores, os 10 tópicos a serem explorados são:

1. Flexibilização do currículo: o intuito é abrir espaço para trabalhar os temas emergentes da sociedade, dentre eles, os direitos humanos, a igualdade social, a sustentabilidade, as questões de gênero e a tecnologia, temas que fazem parte da vida dos estudantes e precisam ser contemplados pela grade curricular das escolas.

2. Uso coerente da tecnologia: os estudantes são estimulados usar a tecnologia para realizar pesquisas acadêmicas, com intuito de incitar o desenvolvimento do pensamento crítico, a capacidade de argumentação e incentiva-se as atividades em grupo.

3. Incentivo à solidariedade: em 2019, não há mais espaço para preconceitos. A solidariedade deve ser contemplada pelo currículo escolar para ser praticada pelos alunos.

4. Ampliação dos espaços escolares: a aprendizagem deve transpor as barreiras da sala de aula e ocorrer em espaços não convencionais, como pátios, corredores, jardins, quadras de esportes, salas de cinema e laboratórios.

5. Exercício de diálogo e de escuta: é preciso praticar um diálogo em que as pessoas saibam se expressar, e que também percebam a necessidade de escutar diferentes pontos de vista sobre um mesmo assunto.

6. Qualidade na saúde física e psicológica: a saúde física e mental dos alunos e do professor é fundamental para garantir o aprendizado.

7. A vez dos games: a gamificação é outra tendência para a educação nos próximos anos, por meio de jogos de tabuleiros, cartas ou de games, é possível avaliar as principais habilidades dos alunos, pois o feedback é instantâneo.

8. Power pupils em ação: os power pupils, estudantes empoderados e agentes de transformação, são crianças e jovens que estão tomando conta das salas de aula. É necessário criar metodologias que canalizem o empoderamento dessas pessoas.

9. Metodologias ativas: estratégias que incentivem a participação dos estudantes

1 FINEP: Financiadora de Estudos e Projetos, é uma empresa pública brasileira de fomento à ciência, tecnologia e inovação em empresas, universidades, institutos tecnológicos e outras instituições públicas ou privadas, sediada no Rio de Janeiro. 
também são tendência na educação. São exemplos: sala de aula invertida, aprendizagem por projeto, aprendizagem por problemas, aprendizagem por pares, dentre outros, inclusive citados por nós.

10. Empreendedorismo: incentivar o empreendedorismo nas escolas vai além de formar futuros empresários, significa desenvolver habilidades como criatividade, autonomia, responsabilidade, além da capacidade de resolver problemas e de inovar.

Em um cenário que a metodologia de ensino e aprendizagem seria totalmente diferente, uma ementa de disciplina, focada em uma lista de conteúdos, não era suficiente. Então o primeiro passo do processo de transformação foi reescrever a ementa, indicando para quem aquela disciplina foi desenvolvida, o que o estudante faria durante o semestre e fechando com quais os resultados de aprendizagem, ou seja, o que o estudante seria capaz de fazer no final do semestre. A nova ementa ficou descrita da seguinte forma: "A disciplina é ofertada para estudantes do curso de Design de Moda que tenham cursado a disciplina de Tecnologia Têxtil. Ao longo do semestre os estudantes realizam pesquisas e atividades práticas de análise e construção de amostras têxteis relacionando seus tipos, processos produtivos e beneficiamentos a partir das fibras e fios com as propriedades dos tecidos e que indicarão suas características e recomendações de uso. Ao final é capaz de selecionar o material ideal para criação de produtos de moda em situações específicas, com foco em sustentabilidade, tecnologia e inovação". (SENA, 2018b)

Com objetivo de atingir os resultados traçados, a disciplina foi totalmente restruturada com diferentes atividades. Os estudantes foram organizados em times que perdurariam todos o semestre com base nas estratégias de TBL (aprendizagem baseada em times). Os times foram organizados a partir das respostas de um questionário sobre seus modelos mentais, a proposta foi montar times com estudantes de modelos mentais diferentes e assim estimular o surgimento da empatia entre os pares e a compreensão de diversas formas de pensar e agir. No TBL, os estudantes são avaliados pelo seu desempenho individual e também pelo resultado do trabalho em grupo, além de se submeterem à avaliação entre os pares, o que incrementa a responsabilização. Os membros têm a oportunidade de avaliar as contribuições individuais para o desempenho da equipe. A avaliação pelos pares é essencial, pois os componentes da equipe são, normalmente, os únicos que têm informações suficientes para avaliar com precisão a contribuição do outro.

A opção metodologias ativas favorece a autonomia dos estudantes, despertando a curiosidade, instigando tomadas de decisões individuais e coletivas, por meio das atividades práticas. Os temas da disciplina foram trabalhados em dois grandes projetos, o primeiro era a construção de um book têxtil que explorasse os processos construtivos, as características e as propriedades dos tecidos. E o segundo tratava da criação de um jogo que abordasse os beneficiamentos têxteis. Para o desenvolvimento dos projetos, os estudantes também passaram pelas experiências de aprendizagem com peer instruction (aprendizagem por pares) e flipped classroom (sala de aula invertida).

Neste artigo, destacamos o uso da gamificação como uma das metodologias eleitas para transformar a disciplina. $\mathrm{O}$ uso de jogos ou estratégias de gamificação tem o intuito de desenvolver a aprendizagem de conteúdos pelo despertar o interesse dos estudantes dentro de um ambiente lúdico, propício a uma melhor aprendizagem, muito diferente das salas de aula tradicionais. 
É muito mais eficiente aprender por meio de jogos e, isso é válido para todas as idades, desde o maternal até a fase adulta. O jogo em si, possui componentes do cotidiano e o envolvimento desperta o interesse do aprendiz, que se torna sujeito ativo do processo, e a confecção dos próprios jogos é ainda muito mais emocionante do que apenas jogar. (LOPES, 2001, p. 23).

A proposta de uso de game ou a sistemática da gamificação deve ser utilizada para além de recompensas ou de medalhas, e deve envolver as pessoas, motivar suas ações, promover a aprendizagem e ajudá-las a resolver problemas. O foco do uso de jogos vem para contribuir com o ensino e com o professor, pois permite aos estudantes desenvolverem o raciocínio para formular as respostas, estimulando-os na construção do conhecimento e também auxilia nas interações estudante/professor, e estudante/estudante, colaborando para a formação social dos mesmos. Na disciplina, optou-se tanto por uso de jogos desenvolvidos pela professora, como o desenvolvimento de um PjBL de construção de jogos sobre beneficiamento têxtil.

Figura 1: Exemplos de jogos desenvolvidos na disciplina.

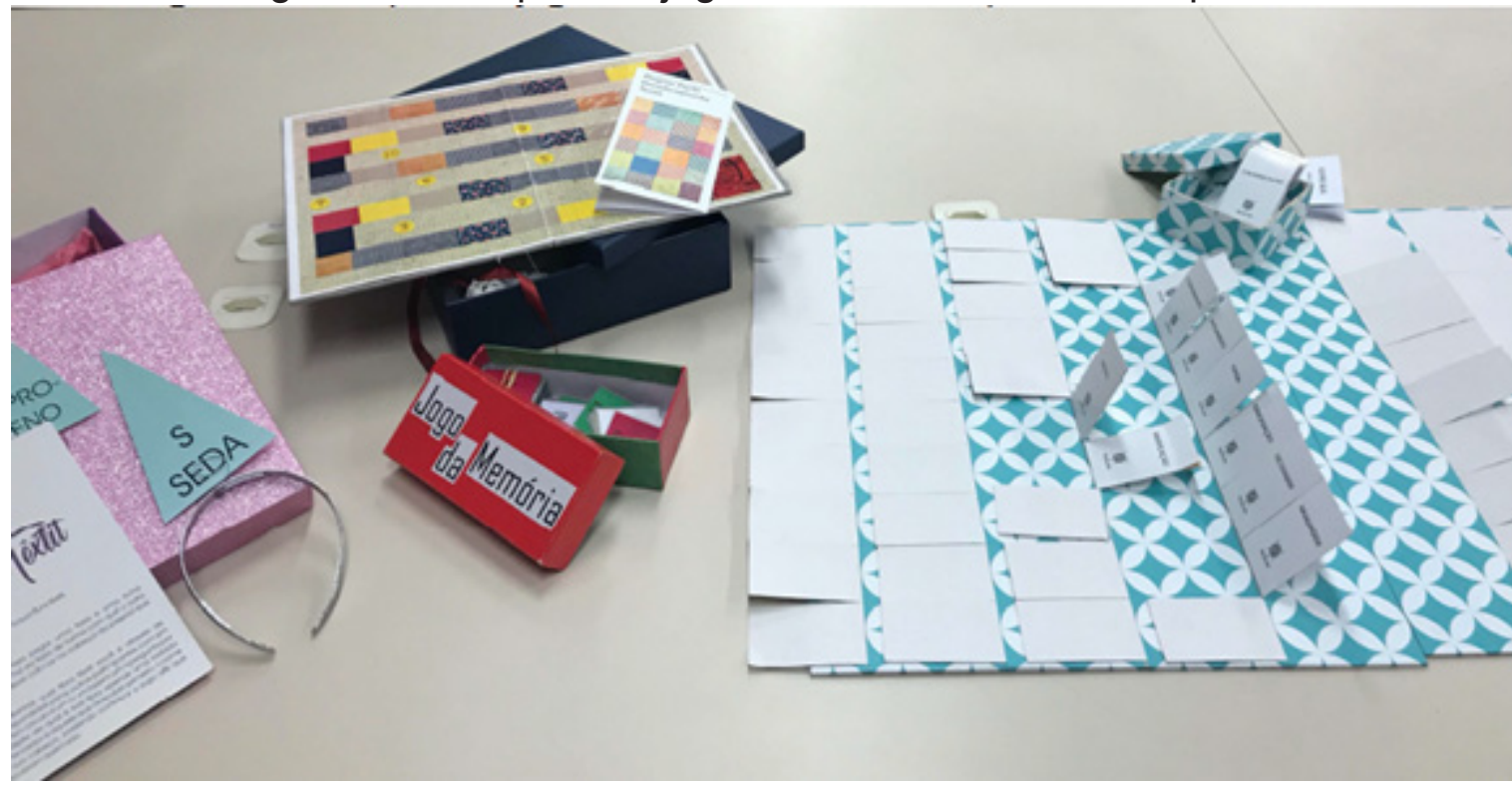

Fonte: Sena, 2018

Os estudantes desenvolveram diversos tipos de jogos (tabuleiros, cartas, perguntas e respostas, aplicativos, dentre outros) para os quais precisaram fazer pesquisa, levantar informações sobre os conteúdos e depois organizá-los de forma coerente e que se enquadrasse na lógica do jogo proposto. As diferentes metodologias proporcionam aos estudantes oportunidades para o desenvolvimento de habilidades que vão além das relacionadas diretamente ao conteúdo das disciplinas. O sucesso do projeto dependeu muito do empenho e engajamento do estudante na realização das atividades. Quando comparado aos semestres anteriores, nos quais $50 \%$ dos estudantes ficavam de exame e destes apenas metade conseguiam aprovação, podemos considerar as mudanças extremamente positivas, sendo que $100 \%$ dos estudantes que concluíram a disciplina tiveram aprovação sem passar por exames. Consideramos, portanto, que atingimos o objetivo de desenvolver autonomia, senso crítico, criatividade, reflexão, poder de argumentação, investigação, técnicas de pesquisa, colaboração e cooperação, habilidades que podem contribuir com a educação continuada, ou seja, a partir dessas habilidades o estudante aprende a aprender. 


\section{CONCLUSÃO}

A mudança no perfil do estudante chama atenção para a necessidade de mudanças na estrutura curricular dos cursos e clama por inovação no processo de ensino e aprendizagem e na sua avaliação para que os estudantes alcance excelência na formação profissional e cidadã e se desenvolva autonomia. No caso apresentado acima, buscamos mostrar um exemplo, dentre tantos outros, como o projeto de uma universidade que quer mudar seus currículos para currículos por competências, precisa estar alinhada e coerente para que tenha sucesso. Na PUCPR as transformações vêm ocorrendo deste 2014, com a formação do CrEAre, que dá treinamento para os professores com oficinas de treinamento em diferentes metodologias, consultoria individual para auxilio de construção de plano de ensino e monitoramento do andamento das disciplinas, cafés mensais para discussão das aplicações de metodologias, simpósio anual de boas práticas docentes, prêmio professor destaque da graduação (que a autora recebeu em 2016 pelo uso de metodologias diferenciadas em sala de aula), fórum anual para discussão das matrizes, mudanças no PDG da instituição e o próprio projeto FINEP, que está na $3^{a}$ edição (cada uma delas com 60 professores aprovados para desenvolvimento do projeto que têm duração de três semestres: o primeiro para preparação da disciplina, segundo de aplicação das modificações e o terceiro com divulgação das boas práticas produzidas durante o projeto).

As metodologias de ensino e avaliação da aprendizagem precisam ser coerentes entre si e com o perfil do egresso que se pretende formar, e devem fazer sentido para o modelo mental de cada universidade. A busca pela excelência pressupõe o alcance de elevado nível técnico na formação profissional, demandando aumento no grau de exigência. $O$ desafio para os docentes é mudar suas estratégias, pois para desenvolver competências é necessário trabalhar elaborando problemas e projetos, propondo tarefas complexas, que desafiem e estimulem os estudantes a mobilizarem seus conhecimentos para completá-las.

A mudança passa pelo modelo de educação colaborativa, interagindo o conhecimento do professor com do estudante, e assim a aula se torna mais estimulante e atrativa e os resultados são produção de conhecimento e aprendizagem significativa. As experiências adquiridas com uso de metodologias que promovem aprendizagem ativa foram enriquecedoras e estimulantes. Esse fato é que nos motiva continuar nosso trabalho. É importante salientar que a simples utilização destas metodologias não garante a aprendizagem dos conteúdos se não houver uma análise antecipada do professor, para que ele possa melhor utilizar essa prática.

\section{REFERÊNCIAS}

BRASILIANO, Antônio Celso Ribeiro. Mundo Vica. Volátil. Incerto. Complexo. Ambíguo. Rio de Janeiro: QualityMark. 2014

BEHRENS, Marilda Aparecida.; JOSÉ, Eliane Mara Age. Aprendizagem por projetos e os Contratos didáticos. Revista Diálogo Educacional, v. 2, n.3, 2001. Disponível em:<http://www2.pucpr.br/reol/pb/index.php/dialogo?dd1=724\&dd99=view\&dd98=pb> Acesso em: 11 mai. 2018 
COOLHUNTING COMMUNITY. 10 Tendências em educação. Madri. 2016. Disponível em https://www.cicae.com/wpcontent/uploads/2017/10/INFORMERESUMENTENDENCIAS-EDUCACIONCOOLHUNTING4.pdf. Acesso em 30 mai de 2018.

COSTA, A. Quatro questões sobre a noção de competências na formação de professores: o caso brasileiro. Revista de Educação. 2004. no 12.

DALLAN Ermelinda Maura Chezzi. Competências e Habilidades (ferramentas): Como planejar por competências. Nova Escola: A Revista do Professor. São Paulo. Setembro de 2000.

DETERDING, S. Gamification: using game design elements in non-gaming contexts. In: CONFERENCE ON HUMAN FACTORS IN COMPUTING SYSTEMS, 2011, Vancouver, Canada. Proceedings... Vancouver, 2011. p. 1-4.

EDUCAUSE. Things you should know about flipped classrooms. 2012. Disponível em: http://net.educause.edu/ir/library/pdf/eli7081.pdf. Acessado em: julho 2017.

FELDER, Richard M.; BRENT, Rebecca. Active Learning: An Introduction. ASQ Higher Education Brief, v.2, n.4, 2009. Disponível em: <http://www4.ncsu.edu/unity/lockers/ users/f/felder/public/Papers/ALpaper(ASQ).pdf>. Acesso em: 06 Set. 2013.

FONSECA, Adriana. Estudo mapeia competências profissionais exigidas nos próximos anos. Valor Econômico. Disponível em: <http://www.valor.com.br/carreira/2759010/estudo-mapeia-competencias-profissionais-exigidas-nos-proximos-anos>. Acesso em: 14 Abr. 2018.

HUIZINGA, Johan. Homo ludens: o jogo como elemento da cultura São Paulo: Perspectiva, 1971.

LEITE, D. et al. Estudantes e avaliação da universidade: um estudo conjunto Brasil Por tugual. Caderno de Pesquisa, São Paulo, v. 37, n. 132, p. 661-686, set./dez., 2007.

LEITE, J. F. N. A formação do psicólogo: clínica, social e mercado. São Paulo: Escuta, 2004.

LOPES, M. da G. Jogos na Educação: criar, fazer e jogar. $4^{\circ}$ Edição revista, São Paulo: 2001.

MANZUR, Eric. Peer Instruction: A revolução da aprendizagem ativa [recurso eletrônico]. Tradução: Anatólio Laschuk. Porto Alegre. Penso, 2015. E-PUB

OECD (2014), PISA 2012 Results: Creative Problem Solving: Students' Skills in Tackling Real-Life Problems (Volume V), PISA, OECD Publishing. Disponível em:< http://www. oecd.org/pisa/keyfindings/pisa-2012-results-overview.pdf>. Acesso em: 14 Abr. 2018. 
PRINCE, Michael. Does Active Learning Work? A Review of the Research. Journal of Engineering Education, v. 93, n.3, p. 223-231, 2004. Disponível em: <http://ctlt.jhsph. edu/resources/views/content/files/150/Does_Active_Learning_Work.pdf>. Acesso em: 06 Set. 2018.

PERRENOUD, Philippe. Porquê construir competências a partir da escola? Porto: Edições Asa. 2001.

PUCPR. Plano de Desenvolvimento da Graduação (PDG) - 2018. Disponível em: https://www.pucpr.br/estatico/pdg/\#!/profissionais-competentes Acesso em: 2 dez 2018.

SCALLON, Gérard. Avaliação da Aprendizagem Numa Abordagem por Competências. Curitiba: PUCPRPress. 2015

SENA, Taísa Vieira. Plano de ensino da disciplina de tecnologia têxtil aplicada. Design de Moda - PUCPR, 2018a.

SENA, Taísa Vieira. Tendências Em Educação: metodologias ativas no ensino superior. In Anais $14^{\circ}$ Colóquio de Moda. Curitba: Abepem. set $2018 \mathrm{~b}$.

YADAV, Aman et al. Problem-based Learning: Influence on Students' Learning in an Electrical Engineering Course. Journal of Engineering Education, v.100, n.2, p. 253-280, 2011. Disponível em: <http://doi.wiley.com/10.1002/j.2168-9830.2011.tb00013.x>. Acesso em: 01 Abr. 2018.

Recebido em: 19/03/2019

Aceito em: 24/04/2019

DOI: http://dx.doi.org/10.5965/25944630322019025 